\title{
Adolescent Health Literacy: The Importance of Credible Sources for Online Health Information
}

\author{
Suad F. Ghaddar, PhD ${ }^{a}$ Melissa A. Valerio, PhD ${ }^{b}$ Carolyn M. Garcia, PhDc Lucy Hansen, MLis ${ }^{d}$
}

ABSTRACT

BACKGROUND: Little research has examined adolescent health literacy and its relationship with online health information sources. The purpose of this study is to explore health literacy among a predominantly Hispanic adolescent population and to investigate whether exposure to a credible source of online health information, MedlinePlus ${ }^{\circledR}$, is associated with higher levels of health literacy.

METHODS: An online survey was administered to a cross-sectional random sample of high school students in South Texas. Self-reported sociodemographic characteristics and data on health-information-seeking behavior and exposure to MedlinePlus ${ }^{\circledR}$ were collected. Health literacy was assessed by eHEALS and the Newest Vital Sign (NVS). Linear and binary logistic regressions were completed.

RESULTS: Of the 261 students who completed the survey, $56 \%$ had heard of MedlinePlus ${ }^{\circledR}, 52 \%$ had adequate levels of health literacy as measured by NVS, and the mean eHEALS score was 30.6 (possible range 8-40). Health literacy was positively associated with self-efficacy and seeking health information online. Exposure to MedlinePlus ${ }^{\circledR}$ was associated with higher eHealth literacy scores $(p<.001$ ) and increased the likelihood of having adequate health literacy (odds ratio: $2.1 ; 95 \%$ $\mathrm{Cl}: 1.1,4.1)$.

CONCLUSION: Exposure to a credible source of online health information is associated with higher levels of health literacy. The incorporation of a credible online health information resource into school health education curricula is a promising approach for promoting health literacy.

Keywords: health literacy; MedlinePlus ${ }^{\circledR}$; health informatics; health communication; child and adolescent health.

Citation: Ghaddar SF, Valerio MA, Garcia CM, Hansen L. Adolescent health literacy: The importance of credible sources for online health information. J Sch Health. 2012; 82: 28-36.

$\mathrm{H}$ ealth literacy is commonly defined as "the degree to which individuals have the capacity to obtain, process, and understand basic health information and services needed to make appropriate health decisions." ${ }^{\prime}$ Few studies have focused on adolescent health literacy in general, and fewer within the school environment in particular. Adolescents are generally healthy and, as such, they do not navigate the health care system as extensively as adults. ${ }^{2}$ Understanding and promoting health literacy among adolescents, however, is essential for multiple reasons: (1) adolescents are developing lifelong health behaviors and habits, and adequate health literacy skills may support informed health-seeking lifestyles; (2) adolescents are future independent health care system users, and young adults who are health literate may contribute to a generation-level reduction of poor health outcomes known to be associated with low health literacy among adults; ${ }^{3-7}$ (3) adolescents are gradually being provided with access to online health services as more health systems rely on Internetbased services; ${ }^{8}$ and (4) the few studies investigating adolescent literacy and health literacy have shown that low literacy/health literacy is associated with risky behaviors including tobacco use, ${ }^{9}$ problem behaviors (eg, aggression, gun carrying), ${ }^{10,11}$ obesity, ${ }^{12}$ and lower levels of health-promoting behaviors. ${ }^{13}$

Hispanic adolescents, in particular, are an important group to reach and target with health literacy interventions because they represent the fastest growing segment of the population and belong to an ethnic group with lower average health literacy than any other ethnic group. ${ }^{14}$ Within the context of minority populations with low levels of educational attainment, a focus on adolescents' literacy may aid in addressing health disparities

aAssociate Director, (sghaddar@utpa.edu), South Texas Border Health Disparities Center, The University of Texas-Pan American, 2925 Pine Valley Drive, Harlingen, TX 78550.

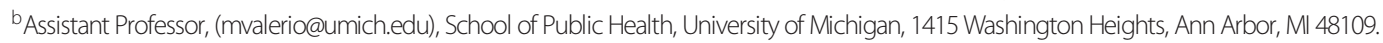


during a key transitional and developmental stage. Marginalized minority populations have an especially high prevalence of low health literacy; ${ }^{15}$ these same populations are also at greater risk of developing chronic disease and suffer disproportionally from health disparities. ${ }^{1}$

Understanding health literacy, specifically within the context of online health-information-seeking behaviors, has particular relevance for young people. Adolescents in the 21 st century rely on technology much more than their adult counterparts for communication, accessing information, and generally, living life (eg, social Web sites, texting, and instant messaging). ${ }^{16}$ Several studies have investigated adolescents' use of the Internet for healthrelated information, ${ }^{17-23}$ yet to our knowledge, none to date have examined the association of online health-information-seeking behaviors and health literacy levels. This relationship is important because it can inform the design of developmentally relevant interventions that promote health literacy for this age group by building on a known adolescent asset, namely, technological and Internet skills. The purpose of this study was to explore the determinants of health literacy among predominantly Hispanic adolescents and to investigate whether exposure to a reliable and valid source of online health information, MedlinePlus ${ }^{\circledR}$, is associated with better health literacy. We hypothesize that health literacy would be higher among adolescents exposed to MedlinePlus ${ }^{\circledR}$ as compared to those not exposed to this resource.

\section{METHODS}

\section{Participants}

Participants included high school students from the South Texas Independent School District (STISD), a magnet public school district serving 3 Texas-Mexico border counties. STISD is comprised of 4 high schools and a middle school. Two of the high schools focus on careers in medical professions, 1 on careers in science and engineering, and the fourth on careers in business, education, and technology. STISD had 3023 students during the 2009-2010 academic year. Eighty percent of the student body was Hispanic and 58\% was economically disadvantaged. ${ }^{24}$

The study sample was recruited from STISD because the district has, since 2001, introduced MedlinePlus ${ }^{\circledR}$, a health information Web site developed and maintained by the National Library of Medicine, to students through curricular training or 2-week summer institutes. ${ }^{25,26}$ In addition, some teachers had incorporated MedlinePlus ${ }^{\circledR}$ as a tool into some health education and health technology class curricula. Thus, the district contained a sizable number of students who had heard of and utilized MedlinePlus ${ }^{\circledR}$, allowing for the testing of the study hypothesis. Comparatively, a sampling of 170 students from a different school district revealed that only $9 \%$ of the students had heard of MedlinePlus ${ }^{\circledR}$.

\section{Procedure}

Fourteen classrooms corresponding to 4 freshmen, 4 sophomore, 3 junior, and 3 senior classrooms, were randomly selected. A letter of invitation for study participation was mailed by the school to parents of students in the selected classrooms. The letter outlined study objectives and procedures and provided instructions for parental review of the survey, should a parent be interested in reviewing the survey instrument. The letter asked parents to sign and return the enclosed study form only if they objected to their child's participation in the survey. Otherwise, consent was implied; the opt-out procedure allowed for parental decision regarding participation. This type of consent increases participation rates and minimizes non-response bias. $^{27}$ The letter allowed for a 2 week window for parental response. Recruitment letters and consent forms were in both English and Spanish.

Students completed the surveys online in a computer lab at each school; S. F. Ghaddar oversaw the process to ensure a systematic data collection protocol. Oral and written instructions for the survey emphasized confidentiality, anonymity, and the importance of working independently. Instructions also stressed voluntary participation. Students completed the surveys in 15-25 minutes and received a \$10 gift card from a local bookstore. Data were collected in February 2010.

\section{Instruments}

The survey instrument included 52 questions assessing: (1) sociodemographic and academic information, (2) patterns of Internet use, (3) health information,

\footnotetext{
cAssistant Professor, (garcia@umn.edu), School of Nursing, University of Minnesota, 5-140 Weaver Densford Hall, 308 Harvard Street SE, Minneapolis, MN 55455.

¿Lead Librarian, (lucy.hansen@stisd.net), Biblioteca Las Américas, South Texas Independent School District, 100 Med High Drive, Mercedes, TX 78570.

Address correspondence to: Suad F. Ghaddar, Associate Director, (sghaddar@utpa.edu), South Texas Border Health Disparities Center, The University of Texas-Pan American, 2925 Pine Valley Drive, Harlingen, TX 78550.

The authors would like to thank the administration, faculty, and staff of the South Texas Independent School District (STISD) for their help and support during this study. Special thanks go to Ann Vickman and Sara Reibman for sharing information and insights from the jVVA! Peer Tutor Program. This research was funded by a grant from the Centers for Disease Control and Prevention (Grant H75DP001812). The contents of this presentation are solely the responsibility of the authors and do not necessarily represent the official views of the Centers for Disease Control and Prevention or the South Texas Border Health Disparities Center at The University of Texas-Pan American.
} 
(4) MedlinePlus ${ }^{\circledR}$ use, (5) general self-efficacy, (6) eHealth literacy, and (7) nutrition label literacy (Newest Vital Sign).

Sociodemographic and Academic Information. We collected data on age, gender, race/ethnicity (dichotomized as Hispanic versus other), and socioeconomic status (question on whether student qualified for free lunch; Yes/No dichotomous format). Additional academic information included grade level and enrollment in health courses.

Health-Related Information Seeking. We asked about health-information-seeking behaviors to identify adolescents' likelihood to use everyday sources of health-related information, such as family, friends, Internet ( 1 to 5 scale; $1=$ not at all likely, $5=$ very likely), use of online health sources to check health-related information (Yes/No dichotomous format), and provision of interpretation services between health care providers and family members (Yes/No dichotomous format).

MedlinePlus $^{\circledR}$ Exposure. We measured knowledge of MedlinePlus ${ }^{\circledR}$ as a dichotomous variable set at 1 if students had heard of the health information Web site and 0 otherwise.

Self-Efficacy. We used the General Self-Efficacy Scale, a 10-item scale, to assess "self-beliefs to cope with a variety of difficult demands in life." 28 Respondents indicated their level of agreement on a 5 -point scale ( $1=$ not at all true, $5=$ exactly true). The summation of responses indicated adolescents' perceived level of self-efficacy, with higher scores reflecting higher levels of self- efficacy. Cronbach's $\alpha$ for the scale was .87.

Health Literacy. We used 2 measures of health literacy, eHEALS ${ }^{29}$ and the Newest Vital Sign (NVS). ${ }^{30}$

eHealth Literacy Scale. eHEALS is an 8-item eHealth literacy scale designed "to measure consumers' combined knowledge, comfort, and perceived skills at finding, evaluating, and applying electronic health information to health problems." 29 Respondents indicated their level of agreement on a 5-point scale $(1=$ strongly disagree, $5=$ strongly agree $)$. The summation of responses indicated the level of eHealth literacy, with higher scores reflecting higher levels of eHealth literacy. Cronbach's $\alpha$ for the scale was .90.

Newest Vital Sign. The NVS is an instrument that uses an ice-cream nutrition label and 6 health literacy and numeracy assessment questions. We based scoring on the number of questions answered correctly per the instrument scoring instructions and key. Students who answered 0 to 1 questions correctly were considered highly likely to suffer from limited literacy. Those with 2 to 3 correct answers were classified as having the possibility of limited literacy. Students with 4 to 6 correct answers were considered to possess adequate health literacy.

\section{Data Analysis}

Data analyses, using SPSS 17.0 (SPSS Inc., Chicago, IL), included (1) univariate tests ( $\chi^{2}$ and ttests) to examine differences between students' health literacy levels across sociodemographic and online healthinformation-seeking characteristics, and (2) multivariate tests (linear and binary logistic regressions) to determine the association between knowledge of MedlinePlus ${ }^{\circledR}$ and health literacy levels. Models were fit using forward stepwise selection. Significance level for variable inclusion (exclusion) was set at $p<.05$ $(\mathrm{p}>.075)$.

\section{RESULTS}

\section{Sample Characteristics}

The 14 selected classrooms included 305 students of whom $280(92 \%)$ participated in the study. The 25 -student differential reflected parental objections (3 students), undeliverable parental letters (2), and student absences on survey administration dates (20). Participants' age ranged from 14 to 20 years with a mean of 16 years. Of the 280 students, 261 students had complete data on the variables of interest. Table 1 summarizes participant characteristics for the total sample $(\mathrm{N}=261)$ and by MedlinePlus ${ }^{\circledR}$ exposure $(\mathrm{N}=146)$. Forty percent of the respondents were male. Slightly more than half of the students $(56 \%)$ were from the 2 medical-focused campuses. More students were 1 th graders $(37 \%)$ compared to 9th $(22 \%)$, 10th $(28 \%)$, and 12th graders $(13 \%)$. Most students identified themselves as Hispanic $(84 \%)$ and $61 \%$ qualified for free lunch. The majority (86\%) had completed or were currently enrolled in a health course.

Health-Information-Seeking and Self-Efficacy. Students were actively involved in online health information seeking; $71 \%$ of respondents were very likely to search the Internet for information on a health topic of interest (not reported in table), $81 \%$ had checked health information online, and 59\% had sought health information related to a family member's health online. Students were also actively involved in their families' health encounters, with over half $(55 \%)$ indicating they had provided interpretation between a family member and a health care provider. This is consistent with parent language use data where almost half of Hispanic students rated their parents' language use as "only Spanish" or "Spanish better than English" (not reported in table). Students demonstrated moderately high levels of self-efficacy, with scores ranging from 22 to 50 (mean $=38.9)$.

Health Literacy. eHEALS scores ranged from 8 to 40 with an average of 30.6. Over half $(52 \%)$ of the respondents answered 4 or more NVS questions correctly, indicating adequate levels of health literacy. Only $11 \%$ had a high likelihood 


\begin{tabular}{|c|c|c|c|}
\hline & \multirow{2}{*}{$\begin{array}{c}\text { Total Sample } \\
\text { N (\%)* }\end{array}$} & \multicolumn{2}{|c|}{ Heard of MedlinePlus ${ }^{\circledR}$} \\
\hline & & N (\%)* & p Value ${ }^{\dagger}$ \\
\hline \multicolumn{3}{|l|}{ Gender } & .229 \\
\hline Male & $105(40.2)$ & $54(51.4)$ & \\
\hline Female & $156(59.8)$ & $92(59.0)$ & \\
\hline \multicolumn{3}{|l|}{ School } & $<.001$ \\
\hline Business/education/technology & $78(29.9)$ & $16(20.5)$ & \\
\hline Medical professions 1 & $76(29.1)$ & $75(98.7)$ & \\
\hline Medical professions 2 & $69(26.4)$ & $47(68.1)$ & \\
\hline Science/engineering & $38(14.6)$ & $8(21.1)$ & \\
\hline \multicolumn{3}{|l|}{ Grade level } & $<.001$ \\
\hline 9th or 10 th & $130(49.8)$ & $46(35.4)$ & \\
\hline 11th or 12th & $131(50.2)$ & $100(76.3)$ & \\
\hline \multicolumn{3}{|l|}{ Hispanic } & .425 \\
\hline Yes & $220(84.3)$ & $122(55.5)$ & \\
\hline No & $41(15.7)$ & $24(58.5)$ & \\
\hline \multicolumn{3}{|l|}{ Qualify for free lunch } & .411 \\
\hline Yes & $158(60.5)$ & $87(55.1)$ & \\
\hline No & $103(39.5)$ & $59(57.3)$ & \\
\hline \multicolumn{3}{|l|}{ Taken health course (previously or currently) } & $<.001$ \\
\hline Yes & $225(86.2)$ & $141(62.7)$ & \\
\hline No & $36(13.8)$ & $5(13.9)$ & \\
\hline \multicolumn{3}{|l|}{ Checked health information online } & $<.001$ \\
\hline Yes & $212(81.2)$ & $134(63.2)$ & \\
\hline No & $49(18.8)$ & $12(24.5)$ & \\
\hline \multicolumn{3}{|l|}{ Checked health information related to a family member's health online } & $<.001$ \\
\hline Yes & $154(59.0)$ & $101(65.6)$ & \\
\hline No & $107(41.0)$ & $45(42.1)$ & \\
\hline \multicolumn{3}{|l|}{ Provided interpretation between a family member and a health care provider } & .016 \\
\hline Yes & $143(54.8)$ & $89(62.2)$ & \\
\hline No & $118(45.2)$ & $57(48.3)$ & \\
\hline \multicolumn{3}{|l|}{ Newest Vital Sign } & .004 \\
\hline High likelihood of limited literacy & $29(11.1)$ & $11(37.9)$ & \\
\hline Possibility of limited literacy & $96(36.8)$ & $46(47.9)$ & \\
\hline Adequate literacy & $136(52.1)$ & $89(65.4)$ & \\
\hline \multicolumn{4}{|l|}{ Mean \pm SD (Range) } \\
\hline Self-efficacy ${ }^{\ddagger}$ & $38.9 \pm 6.3(10-50)$ & $39.5 \pm 6.1(10-50)$ & .081 \\
\hline eHEALS ${ }^{\ddagger}$ & $30.6 \pm 5.9(8-40)$ & $32.8 \pm 4.9(8-40)$ & $<.001$ \\
\hline
\end{tabular}

* Percentages may not add up to 100 due to rounding.

${ }^{\dagger}$ The $\chi^{2}$ test was used for categorical variables and the $t$-test for continuous variables. $p$ values reflect the significance of differences between those who had and had not heard of MedlinePlus ${ }^{\circledR}$ across select variables.

${ }^{\ddagger}$ Higher scores on self-efficacy and eHEALS reflect higher levels of perceived self-efficacy and eHealth literacy.

of limited literacy (0-1 questions correct) and 37\% had a possibility of limited literacy (2-3 questions correct).

Exposure to MedlinePlus ${ }^{\circledR}$. Over half $(56 \%)$ of the students had heard of MedlinePlus ${ }^{\circledR}$. Those who had heard of the Web site were more likely to be enrolled on campuses promoting careers in the health care field, to be 11 th graders, to have taken or be currently taking a health course, to be actively involved in seeking health information online, and to have interpreted communication between a family member and a health care provider. Students exposed to the Web site were also more likely to have adequate levels of health literacy as measured by the NVS and to report significantly higher eHEALS scores.

\section{Univariate Test Results}

Table 2 presents student health literacy measures (eHEALS, NVS) by sociodemographic factors, academic factors, and health-information related behaviors. Not surprisingly, eHEALS scores were significantly higher among students from the 2 high schools with a focus on medical education compared to non-medical focused campuses. Students in higher grade levels and those who had taken or were currently taking a health course had higher eHEALS scores relative to freshmen and sophomore students and those who had not taken a health course. Other factors associated with higher eHEALS scores were: online health information seeking, exposure to MedlinePlus ${ }^{\circledR}$, and serving as an interpreter between a family member and a health care provider. More participants with adequate levels 
Table 2. Student Health Literacy Levels, as Measured by eHEALS and the Newest Vital Sign, by Sociodemographic, Academic, and Health-Information-Seeking Characteristics $(\mathrm{N}=261)$

\begin{tabular}{|c|c|c|c|c|c|c|}
\hline & $\begin{array}{l}\text { eHEALS } \\
\text { Score } \\
\text { (Mean) }\end{array}$ & $\underset{\text { Value }^{\dagger}}{p}$ & $\begin{array}{c}\text { High } \\
\text { Likelihood of } \\
\text { Limited } \\
\text { Literacy (\%)* }\end{array}$ & $\begin{array}{l}\text { Possibility of } \\
\text { Limited } \\
\text { Literacy }(\%)^{*}\end{array}$ & 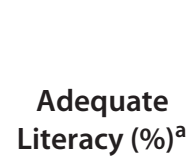 & $\begin{array}{c}p \\
\text { Value }^{t}\end{array}$ \\
\hline Total Sample & 30.6 & & 11.1 & 36.8 & 52.1 & \\
\hline Gender & & .746 & & & & .210 \\
\hline Male & 30.5 & & 11.4 & 30.5 & 58.1 & \\
\hline Female & 30.7 & & 10.9 & 41.0 & 48.1 & \\
\hline School focus & & $<.001$ & & & & $<.001$ \\
\hline Business/education/technology & 28.6 & & 12.8 & 42.3 & 44.9 & \\
\hline Medical professions 1 & 33.1 & & 1.3 & 30.3 & 68.4 & \\
\hline Medical professions 2 & 31.6 & & 20.3 & 47.8 & 31.9 & \\
\hline Science/engineering & 28.1 & & 10.5 & 18.4 & 71.1 & \\
\hline Grade level & & $<.001$ & & & & .001 \\
\hline 9th or 10th & 29.2 & & 15.4 & 43.8 & 40.8 & \\
\hline 11th or 12th & 32.0 & & 6.9 & 29.8 & 63.4 & \\
\hline Hispanic & & .480 & & & & $<.001$ \\
\hline Yes & 30.5 & & 11.8 & 41.4 & 46.8 & \\
\hline No & 31.2 & & 7.3 & 12.2 & 80.5 & \\
\hline Qualify for free lunch & & .274 & & & & $<.001$ \\
\hline Yes & 30.3 & & 5.8 & 27.2 & 67.0 & \\
\hline No & 31.1 & & 14.6 & 43.0 & 42.4 & \\
\hline Taken health course (previously or currently) & & .004 & & & & .662 \\
\hline Yes & 31.0 & & 10.7 & 37.8 & 51.6 & \\
\hline No & 28.0 & & 13.9 & 30.6 & 55.6 & \\
\hline Checked health information online & & $<.001$ & & & & .024 \\
\hline Yes & 31.5 & & 9.9 & 34.0 & 56.1 & \\
\hline No & 26.9 & & 16.3 & 49.0 & 34.7 & \\
\hline Checked health information related to a family member's health online & & $<.001$ & & & & .866 \\
\hline Yes & 32.1 & & 10.4 & 36.4 & 53.2 & \\
\hline No & 28.4 & & 12.1 & 37.4 & 50.5 & \\
\hline Heard of MedlinePlus ${ }^{\circledR}$ & & $<.001$ & & & & .004 \\
\hline Yes & 32.8 & & 7.5 & 31.5 & 61.0 & \\
\hline No/not sure & 27.9 & & 15.7 & 43.5 & 40.9 & \\
\hline Provided interpretation between a family member and a health care provider & & .002 & & & & .524 \\
\hline Yes & 31.7 & & 10.5 & 39.9 & 49.7 & \\
\hline No & 29.4 & & 11.9 & 33.1 & 55.1 & \\
\hline Newest Vital Sign & & .018 & & & & \\
\hline High likelihood of limited literacy & 29.0 & & - & - & - & \\
\hline Possibility of limited literacy & 29.7 & & - & - & - & \\
\hline Adequate literacy & 31.6 & & - & - & - & \\
\hline \multicolumn{7}{|l|}{ Mean (SD) } \\
\hline Self-efficacy & 38.87 & $7(6.29)$ & 37.0 & 37.6 & 40.2 & .002 \\
\hline Age & 15.95 & $5(1.07)$ & 15.8 & 15.8 & 16.1 & .133 \\
\hline EHEALS & & - & 29.0 & 29.7 & 31.6 & .018 \\
\hline
\end{tabular}

* Percentages may not add up to 100 due to rounding.

${ }^{\dagger} p$ values reflect the significance of mean differences in eHEALS scores using $t$-tests, and of group differences in Newest Vital Sign categories using $\chi^{2}$ tests.

of health literacy, as measured by correct answers to the NVS questions, were in upper grade levels (11th or 12 th grade) and attending Medical professions 1 and Science/engineering campuses. Those who were Hispanic and who qualified for free lunch were more likely to report limited literacy levels compared to non-Hispanics and those who did not qualify for free lunch. Having looked for health information online and having heard of MedlinePlus ${ }^{\circledR}$ were associated with adequate levels of health literacy as well. Both measures of health literacy exhibited significant associations, whereby adolescents who answered 4 or more NVS questions correctly had significantly higher eHEALS scores.

\section{Multivariate Test Results}

Table 3 reports results of multiple regression analysis for the eHealth literacy measure. eHEALS scores were significantly related to exposure to MedlinePlus ${ }^{\circledR} \quad(p<.001)$ and to active involvement in searching for health information online $(p<.01)$. Higher self-efficacy scores were positively 
Table 3. Multiple Linear Regression Results Examining MedlinePlus ${ }^{\circledR}$ Exposure and Other Control Variables as Predictors of eHealth Literacy, as Measured by eHEALS $(\mathrm{N}=261)$

\begin{tabular}{lccr}
\hline & $\boldsymbol{b}(\mathrm{SE})$ & $\boldsymbol{B}$ & $\mathbf{p}$-value \\
\hline Heard of MedlinePlus ${ }^{\circledR}$ & $3.54(0.65)$ & 0.30 & $<.001$ \\
Self-efficacy & $0.27(0.05)$ & 0.29 & $<.001$ \\
Checked health information online & $2.01(0.67)$ & 0.17 & .003 \\
Checked health information related to a & $2.41(0.86)$ & 0.16 & .005 \\
$\quad$ family member's health online & & & \\
Model Statistics & & & \\
Adjusted R & 0.32 & & \\
Model p value & $<.001$ & & \\
\hline
\end{tabular}

related to eHEALS scores $(p<.001)$. Standardized coefficients reveal the relative importance of the variables, with knowledge of MedlinePlus ${ }^{\circledR}$ ranking as the most important factor in determining the level of eHealth literacy, followed closely by self-efficacy.

Table 4 shows the results of the binary logistic model testing the association between adequate levels of health literacy, as measured by NVS, and sociodemographic, academic, and health-informationseeking variables. In general, students who had heard of MedlinePlus ${ }^{\circledR}$ were twice as likely to have adequate health literacy levels than those who had not heard or were not sure whether they had heard of the Web site (odds ratio [OR]: 2.09, 95\% confidence interval [CI]: 1.06, 4.10). Hispanic students were less likely to report adequate levels of health literacy relative to non-Hispanics (OR: 0.20, 95\% CI: 0.08, 0.51). Similarly, younger students (9th and 10th graders) were less likely to have adequate levels of health literacy compared to older students (11th and 12th graders; OR: $0.32,95 \%$ CI: $0.17,0.63)$. Compared to students from the first medical professions campus, students from the second newer medical-focused

Table 4. Binary Logistic Regression Results Examining MedlinePlus ${ }^{\circledR}$ Exposure and Other Control Variables as Predictors of Adequate Health Literacy, as Measured by Newest Vital Sign $(\mathrm{N}=261)$

\begin{tabular}{lrcr}
\hline & $\begin{array}{c}\text { Odds } \\
\text { Ratios }\end{array}$ & $\begin{array}{c}\text { 95\% } \\
\text { Confidence } \\
\text { Intervals }\end{array}$ & p-value \\
\hline Heard of MedlinePlus ${ }^{\circledR}$ & 2.09 & $(1.06,4.10)$ & .032 \\
Hispanic & 0.20 & $(0.08,0.51)$ & .001 \\
Medical professions 2* & 0.40 & $(0.20,0.81)$ & .010 \\
Science/engineering* & 7.01 & $(2.62,18.74)$ & $<.001$ \\
9th or 10th grader & 0.32 & $(0.17,0.63)$ & .001 \\
Self-efficacy & 1.07 & $(1.02,1.12)$ & .008 \\
Checked health information online & 2.90 & $(1.28,6.56)$ & .010 \\
\hline
\end{tabular}

* Medical professions 1 is the reference high school. No significant differences in the likelihood of adequate health literacy were found between Business/education/technology campus and Medical professions 1 students. campus were less likely to have adequate health literacy (OR: 0.40, 95\% CI:0.20, 0.81) and students from the science/engineering campus were more likely to have adequate health literacy (OR: 7.01, 95\% CI: $2.62,18.74)$. Analysis of the data excluding Medical professions 1 students yielded similar and marginally more significant results for the MedlinePlus ${ }^{\circledR}$ variable in both the linear and binary logistic regression models (results not reported).

\section{DISCUSSION}

Given the increased use of and reliance on technology in the adolescent population, it is important to identify how best to promote adolescent health literacy in use of health-related information, especially electronic, or online, information. To our knowledge, this is the first study to explore the association between incorporation of MedlinePlus ${ }^{\circledR}$ knowledge and adolescent health literacy levels. Our results support the importance of introducing adolescents to credible online health information resources. Students who had heard of MedlinePlus ${ }^{\circledR}$ reported higher levels of perceived skills and confidence in looking for health information (eHealth literacy) and more adequate levels of health literacy when compared to students who had not heard of the Web site. The findings are similar to those of studies describing informationskills training programs for health care personnel and their positive impact on information literacy skills and confidence. ${ }^{31}$ It is possible that exposing adolescents to a credible source of health information may overcome or minimize many of the challenges that have been reported by teens searching for health information online, including difficulty in understanding the relevance of information retrieved by search engines and not knowing which sites to trust. ${ }^{21,22,32}$ Directing adolescents to Web site with useful health information may also improve their online searching skills, from a "trial-and-error" approach ${ }^{33}$ to a more systematic and, consequently, successful process.

Our findings also suggest that the promotion of adolescent health literacy may be an important strategy for addressing and minimizing disparities and inequities in health outcomes. Adolescents constitute an important group with whom to intervene because they are not only current dependent users but also future independent users of the health care system. Our study included many Hispanic adolescents residing in Texas-Mexico border communities; increasing adolescent health literacy as a means of addressing health disparities has additional, potentially immediate positive outcomes for their parents, due to the role that these adolescents routinely have in their parents' health encounters. Hispanic adolescents may serve as the window to their parents' health literacy, simply as a result of their English proficiency, computer and 
Internet skills, and in many cases higher educational attainment. In our sample, over half of the teens served as liaisons during health care encounters and sought health information online related to their parents' health. Advancing the health literacy of adolescents is a promising indirect mechanism to addressing health disparities not only for themselves but also for their extended family and community.

\section{Limitations}

Although this study provides valuable insight into the potential role and influence of credible sources of online health information on adolescent health literacy, there are several limitations to consider. First, this is a cross-sectional study, where findings do not reflect causality, but mere associations. Cross-sectional analysis, however, allows for exploration of the health information needs of a certain population. In addition, similar to other studies attempting to capture complex processes with simple measurement instruments, our study has some measurement limitations. Health literacy is a complex construct that encompasses multiple dimensions (functional, critical, and interactive) ${ }^{34}$ and skills (print, oral, and, more recently, Internet-based information seeking); ${ }^{35}$ almost all measures of this construct have some shortcomings. ${ }^{36}$ Our study used 2 measures of health literacy, each with potential limitations. The eHEALS is an instrument that was developed and reported to demonstrate a high level of reliability, but, to our knowledge, was not validated against other more commonly used health literacy measures. A possible reason for the lack of validation studies may be that eHEALS attempts to assess dimensions other than reading and numeracy competencies, traditionally the focus of health literacy measures. As researchers are recognizing the importance of the newer electronic context of health literacy, more measures are being developed to incorporate that dimension. ${ }^{35}$ For NVS, our second measure of health literacy, a potential limitation may stem from administering the instrument online; NVS was developed to be administered orally within primary care settings. However, given the controlled environment within which the instrument was administered, whereby participants completed the surveys independently and were supervised to ensure adherence to this requirement, the online administration did not compromise the results. This is reinforced by the distribution of NVS scores that is similar to other studies for this age group ${ }^{37}$ and the significant relationships with variables commonly associated with health literacy in the literature.

The digital divide and its potential impact on disparities in online health information seeking may be another limitation influencing health literacy levels. To account for potential effects of the digital divide, the multivariate models included a proxy for socioeconomic status, "qualify for free lunch." This variable was not significant, suggesting that health literacy is unrelated to economic disparities for this group. Furthermore, recent studies have shown that, within the context of health information seeking, low parental educational attainment was unrelated or negatively correlated with health information seeking among teen children. ${ }^{38}$ This further supports the belief that younger generations may be insulated from the digital divide while possibly bridging the gap for their parents who may be subject to its impact. Inadequate media literacy may also influence individuals. However, a high number of adolescents have high rates of media use ${ }^{16}$ and, therefore, may be more comfortable in using such resources. Training will be necessary to address appropriate and effective health information seeking and information use.

\section{Conclusion}

As researchers are forecasting an increase in the number of people with limited health literacy, it is critical that the health literacy of younger generations be promoted. Adolescents are using the Internet to obtain health information related to their personal and family members' health. The introduction of a reliable source of health information, such as MedlinePlus ${ }^{\circledR}$, has promise for the improvement of adolescent health literacy.

\section{IMPLICATIONS FOR SCHOOL HEALTH}

Our study points to significant associations between knowledge of MedlinePlus ${ }^{\circledR}$ and health literacy. Findings highlight the importance of updating schoolbased curricular approaches in health education to account for newer dimensions of health-informationseeking behaviors among adolescents. Traditional approaches have focused heavily on the direct (often print) delivery of health information to students; newer approaches however, should focus on the development of critical analysis skills necessary for students to obtain and evaluate health information in a world where access to information is no longer a challenge. School administrators in partnership with health educators (ie, teachers, nurses, social workers) may benefit from an evaluation of currently used health education curricula to address the widening gap between current presentation of health information in the classroom and actual health-information-seeking behaviors of students. Future efforts should be directed toward the development of an educational curriculum which builds on study findings and other school-based health literacy research. ${ }^{39,40}$

A systematic approach to the promotion of health literacy necessitates a well-developed curriculum, administrative support for implementation by 
knowledgeable staff, and an evaluation component. A curriculum module should focus on skills for identification of credible sources for online health information and promote training for effective health information seeking. Administrative support is instrumental to ensure adoption and provision of resources that facilitate staff development. Finally, an evaluation strategy is necessary to assess whether the newer approach has an impact on targeted outcomes, including overall student learning and, more importantly, their levels of health literacy. School systems, recognized as potential intervention points ${ }^{1,34}$ are an ideal setting for the promotion of health literacy, which in turn may result in healthier lifestyles and long-term outcomes for adolescents.

\section{Human Subjects Approval Statement}

This study was approved by The University of TexasPan American's institutional review board.

\section{REFERENCES}

1. Nielsen-Bohlman L, Panzer AM, Kindig DA. Health Literacy: A Prescription to End Confusion. Washington, DC: Institute of Medicine: National Academies Press; 2004:345.

2. Newacheck PW, Wong ST, Galbraith AA, Hung Y. Adolescent health care expenditures: a descriptive profile. J Adolesc Health. 2003;32(6 suppl 1):3-11.

3. DeWalt DA, Pignone MP. Health literacy and health outcomes: overview of the literature. In: Schwartzberg JG, VanGeest JB, Wang CC, eds. Understanding Health Literacy: Implications for Medicine and Public Health. Chicago: AMA Press; 2005:205-227.

4. Schillinger D, Grumbach K, Piette J, et al. Association of health literacy with diabetes outcomes. JAMA. 2002;288(4):475-482.

5. Gazmararian JA, Williams MV, Peel J, Baker DW. Health literacy and knowledge of chronic disease. Patient Educ Couns. 2003;51(3):267-275.

6. Baker DW, Parker RM, Williams MV, Clark WS. Health literacy and the risk of hospital admission. J Gen Intern Med. 1998;13(12):791-798.

7. Cho YI, Lee SY, Arozullah AM, Crittenden KS. Effects of health literacy on health status and health service utilization amongst the elderly. Soc Sci Med. 2008;66(8):1809-1816.

8. Moreno MA, Ralston JD, Grossman DC. Adolescent access to online health services: perils and promise. J Adolesc Health. 2009;44(3):244-251.

9. Conwell LS, O'Callaghan MJ, Andersen MJ, Bor W, Najman JM, Williams GM. Early adolescent smoking and a web of personal and social disadvantage. J Paediatr Child Health. 2003;39(8):580-585.

10. Davis TC, Byrd RS, Arnold CL, Auinger P, Bocchini JA, Jr. Low literacy and violence among adolescents in a summer sports program. J Adolesc Health. 1999;24(6):403-411.

11. Miles SB, Stipek D. Contemporaneous and longitudinal associations between social behavior and literacy achievement in a sample of low-income elementary school children. Child Dev. 2006;77(1):103-117.

12. Sharif I, Blank AE. Relationship between child health literacy and body mass index in overweight children. Patient Educ Couns. 2010;79(1):43-48.

13. Chang LC. Health literacy, self-reported status and health promoting behaviours for adolescents in Taiwan. J Clin Nurs. 2011:20(1-2):190-196.
14. Kutner M, Greenberg E, Jin Y, Paulsen C. The Health Literacy of America's Adults: Results from the 2003 National Assessment of Adult Literacy (NCES 2006-483). U.S. Department of Education. 2006.

15. Schwartzberg JG, VanGeest JB, Wang CC, eds. Understanding Health Literacy: Implications for Medicine and Public Health. Chicago, IL: AMA Press; 2005.

16. Lenhart A, Purcell K, Smith A, Zickuhr K. Social Media $\theta$ Mobile Internet Use Among Teens, and Young Adults. PewInternet. Available at: http://pewinternet.org/Reports/2010/SocialMedia-and-Young-Adults.aspx. Accessed November 5, 2010.

17. Bleakley A, Merzel CR, VanDevanter NL, Messeri P. Computer access and Internet use among urban youths. Am J Public Health. 2004;94(5):744-746.

18. Borzekowski DL, Rickert VI. Adolescent cybersurfing for health information: a new resource that crosses barriers. Arch Pediatr Adolesc Med. 2001;155(7):813-817.

19. Gray NJ, Klein JD, Cantrill JA, Noyce PR. Adolescent girls' use of the Internet for health information: issues beyond access. J Med Syst. 2002;26(6):545-553.

20. Gray NJ, Klein JD, Noyce PR, Sesselberg TS, Cantrill JA. Health information-seeking behaviour in adolescence: the place of the internet. Soc Sci Med. 2005;60(7):1467-1478.

21. Gray NJ, Klein JD, Noyce PR, Sesselberg TS, Cantrill JA. The Internet: a window on adolescent health literacy. J Adolesc Health. 2005;37(3):243.

22. Rideout V. Generation Rx.com. What are young people really doing online? Mark Health Serv. 2002;22(1):26-30.

23. Skinner H, Biscope S, Poland B, Goldberg E. How adolescents use technology for health information: implications for health professionals from focus group studies. J Med Internet Res. 2003;5(4):e32.

24. Texas Education Agency. Economically Disadvantaged Status Reports. Available at: http://ritter.tea.state.tx.us/adhocrpt/adstc. html. Accessed October 14, 2010.

25. Warner DG, Olney CA, Wood FB, Hansen L, Bowden VM. High school peer tutors teach MedlinePlus: a model for Hispanic outreach. J Med Libr Assoc. 2005;93(2):243-252.

26. Bowden VM, Wood FB, Warner DG, Olney CA, Olivier ER, Siegel ER. Health information Hispanic outreach in the Texas Lower Rio Grande Valley. J Med Libr Assoc. 2006;94(2):180-189.

27. Courser MW, Shamblen SR, Lavrakas PJ, Collins D, Ditterline $\mathrm{P}$. The impact of active consent procedures on nonresponse and nonresponse error in youth survey data: evidence from a new experiment. Eval Rev. 2009;33(4):370-395.

28. Schwarzer R, Jerusalem M. Generalized Self Efficacy Scale. In: Weinman J, Wright S, Johnston M, eds. Measures in Health Psychology: A User's Portfolio. Windsor, UK: NFER-NELSON; 1995:35-37.

29. Norman CD, Skinner HA. eHEALS: the eHealth literacy scale. $J$ Med Internet Res. 2006;8(4):e27.

30. Weiss BD, Mays MZ, Martz W, et al. Quick assessment of literacy in primary care: the newest vital sign. Ann Fam Med. 2005;3(6):514-522.

31. Trinder VM, Fleet GE, Gray AE. Evaluating the impact of library user training programmes across Thames Valley Strategic Health Authority in the UK. Health Info Libr J. 2007;24(1):34-40.

32. Brown SL, Teufel JA, Birch DA. Early adolescents perceptions of health and health literacy. J Sch Health. 2007;77(1):7-15.

33. Hansen DL, Derry HA, Resnick PJ, Richardson CR. Adolescents searching for health information on the Internet: an observational study. J Med Internet Res. 2003;5(4):e25.

34. Nutbeam D. Health literacy as a public health goal: a challenge for contemporary health education and communication strategies into the 21 st century. Health Promot Int. 2000;15(3):259267. 
35. McCormack L, Bann C, Squiers L, et al. Measuring health literacy: a pilot study of a new skills-based instrument. $J$ Health Commun. 2010;15(suppl 2):51-71.

36. Jordan JE, Osborne RH, Buchbinder R. Critical appraisal of health literacy indices revealed variable underlying constructs, narrow content and psychometric weaknesses. J Clin Epidemiol. 2010;64(4):366-379.

37. Shah LC, West P, Bremmeyr K, Savoy-Moore RT. Health literacy instrument in family medicine: the "newest vital sign" ease of use and correlates. J Am Board Fam Med. 2010;23(2): 195-203.
38. Zhao S. Parental education and children's online health information seeking: beyond the digital divide debate. Soc Sci Med. 2009;69(10):1501-1505.

39. Brey RA, Clark SE, Wantz MS. Enhancing health literacy through accessing health information, products, and services: an exercise for children and adolescents. J Sch Health. 2007;77(9):640-644.

40. Brey RA, Clark SE, Wantz MS. This is your future: a case study approach to foster health literacy. J Sch Health. 2008;78(6): 351-355. 